\title{
Curating Media Learning: Towards A Porous Expertise
}

Julian McDougall, Bournemouth University and John Potter, Institute of Education

Profiles -

http://www.cemp.ac.uk/people/julianmcdougall.php

http://www.ioe.ac.uk/staff/CCMA/LKLB_44.html

\begin{abstract}
This article combines research results from a range of projects with two consistent themes. Firstly, we explore the potential for curation to offer a productive metaphor for the convergence of digital media learning across and between home / lifeworld and formal educational / systemworld spaces - or between the public and private spheres. Secondly, we draw conclusions from these projects to argue that the acceptance of transmedia literacy practices as a cite for rich educational work - in media education and related areas - can only succeed if matched by a convergence of a more porous educator-student expertise.
\end{abstract}

In 1990, in the conclusion to his edited collection 'Watching Media Learning', David Buckingham offered the following rationale for media education pedagogy:

Questions about subjectivity, about students' sense of their own identity, are inextricable from the ways in which they read and use media... We need to provide opportunities for students to explore their emotional investments in the media in their own terms, rather than attempting to replace these by rigorous 'rational' analysis (1990: 224).

More than twenty years on, and firmly into the 'digital age', these questions remain and the need for appropriate pedagogic strategies is, we argue, unresolved. Indeed, the proliferation of media learning and exchange outside of the classroom, enabled at least partly by the internet and social media, obliges us to return to the same (unanswered) questions about reflexive, critical articulations of mediated 'pleasure' in media education that Buckingham et al posed in the previous century and for the analogue age.

The article firstly sets out the various connected strands of this model, substantiated with research evidence. Secondly, this framework will be exemplified in a number of practical and applicable pedagogic strategies, elaborating and building on ideas expressed so far in 'manifesto' form (Fraser and Wardle, 2012, 2013), spanning the ages and stages, spaces and places of contemporary (digital) media education. 



\section{From Watching to Curating: Models and Manifestos}

A Vygotskyian thread was woven through 'Watching Media Learning', employed to sidestep the problematic polarizing of traditional / progressive pedagogies. Most significantly, for the authors of WML in 1990 and for us today, Vygotsky's arguments (1978) about conceptual learning foreground the value of critical reflection on the processes of thinking itself. Buckingham appropriated these ideas to suggest that:

The aim of media education is not merely to enable children to 'read' - or make sense of - media texts, or to enable them to 'write' their own: it must also enable them to reflect systematically on the processes of reading and writing themselves, to understand and to analyse their own activity as readers and writers. (1990: 219)

'Watching Media Learning' was published in 1990, featuring contributions from a number of authors who remain influential figures in the genealogy of media education. In the last year, two publications, preceding the collection in hand, have returned to these perennial concerns. The 'Manifesto for Media Education' (Fraser and Wardle, 2013) project includes a number of the same authors in a collection dealing with, among other themes, such long-standing concerns as media education for social inclusion, the (still) contested notion of 'creativity' and the shift from 'new media literacies' to 'new media expertise'. At the same time, a special issue of the journal Medijske Studije devoted to Media Literacy Research and Policy offers research-based responses to conceptual, pedagogic and policy themes in the context of potential shifts (for literacy and media education) mobilised by digital technology. We make a simple but important point here. Consider the two statements here from the contemporary field in relation to an equivalent from two decades prior:

In short, media literacy, indeed literacy in general, has both an explanatory and a normative agenda. We must ask, first, what do citizens and consumers know about their changing media environment and, further, what should they know? (Livingstone, Papaionnou, Perez and Wiknen, 2012: 8)

Media education needs new forms of research on what it means to be human; it is about making connections between the online and offline self as we attempt to become 'experts' of the (holistic) self and perception(s) of others. (Walters, 2011)

Clearly we need to build from what our students bring to our lessons rather than appear to know all the answers....We need to mobilize the experiences and undertstandings they do have in a way that enables them to find relations between different patterns of thought. (Sefton-Green, 1990: 149-50).

This easy to construct 'history of the present' for media education / literacy serves as more than a 'straw man'. Our critique is founded on an empirical observation - that the sustained debate around and reframing of the (ideal) subject-identity of media education has tended to privilege the 'what' of skills and knowledge over the 'how' of learning, to the extent that (much) more than ten years on from Sefton-Green's suggestion, we are still on the 'working out' of these key design principles. We believe an educational approach to media learning and literacy in the digital age can productively be mobilized by understanding these patterned relations through a model of curation. 


\section{Curatorship and media education}

The rise of the term "curated" to describe the activities of "owners" of social media spaces, blogs and wikis, and the composers of shared music, film and animations, appears to reflect an agentive turn to meta-authorship amongst larger numbers of participants in online media. Certainly it suggests a more complex process than authoring or editing alone. In this context in fact, beyond simply "sharing" a media clip, or even simply a link, lies an intertextual practice which presupposes a designed act of reflexive identity (re) creation. This word "curated" therefore applies equally to a self-originated text as it does to something else collected and shown alongside such a text in the same space onscreen. The way in which these texts and artefacts work together to make meaning represents the new cultural and literacy practice of curatorship. In "Digital Media and Learner Identity (Potter, 2012) the following definition of this new practice is offered:

\footnotetext{
(Whereas previously)...words to describe activities around publication may have been "written" "edited" and/or "produced", it is quite clear that they are inadequate to capture all the self-representational activities or practices in networked, digital culture. The word "curated" does so by subsuming all of those practices and adding others which are possible in social media. This is because curating suggests not just writing or producing but also collecting, distributing, assembling, disassembling, and moving it across different stages; all of which are potential activities in new media production from posting your status in a social networking site through to making a short clip, sharing an online gallery, or any number of other activities. Curating is about knowing how the different forms you are working with work together to make meaning intertextually and for which purposes and audiences they are successful. (Potter, 2012: 5)
}

In writing this article, therefore, we are attempting to position the productive engagement with media by those we teach as a complex and multi-faceted set of activities which cross traditional boundaries of activity even as they subsume them. We are also conscious of the fact that the subject "media", usually positioned as the upstart outsider by the dominant ecology of education in the UK, must now be seen even more as a site for subjectivity and identification and moved towards the centre ground of the struggle to locate for education those cultural values which lie outside traditionally prescribed curricula. This position does not arise from a form of technoevangelism, nor from a simple equation of digital literacy practices with autonomous models, instantly conferring motivation, happiness and qualifications on a grateful mass of children and students (see also Bulfin and Koutsogiannis, 2012 on this). Rather, the imperative lies in realizing what could be achieved by building a bridge between those skills and dispositions evidenced in practices which have been marginalized year on year since in official curricula and proscribed pedagogy since 'Watching Media Learning'.

The difference that "digital" brings for those in the developed world and for those who have the social and economic capital to take part, is an almost immediate access to authorship and validation from a wider mass of people, sometimes even within a community of practice (Wenger, 1998)). We should 
pause to note that whilst this is superficially a generational experience, there are many teachers and lecturers curating their lived experience of pedagogy in new media for themselves and each other well beyond the narrow and bounded worlds of their own performatively proscribed professional activities (see, for example, Teachmeet Wiki, 2013). Nevertheless this pressure to resist knowledge, validation and use of skills beyond the worlds of school is at best wasteful of the potential of new media in education and, at worst, the negation of agency in formal places of learning in developed countries in the new century.

How can schooled media education respond to these opportunities? And how do we know? Recent research into production of media texts in school, in the third space between school and home and at home has reinforced earlier notions of transition between them (see, for example, Haas - Dyson, 1997). This has been re-described as a semi-permeable membrane (Potter, 2011) in order to suggest a layer of ambiguity and complexity which hopefully moves the debate beyond the binaries of home (good) and school (bad) which characterizes so much of the debate about what is and is not possible within school and outside of school (Bulfin \& Koutsogiannis, 2012).

\section{Examples (1): Primary Schools}

Two examples from recent research serve to illustrate some potential for negotiation between lived experience, media and the act of curation in pursuit of pedagogical models. Andrew Burn and Jackie Marsh directed a project which positioned child researchers in two primary schools as curators of their experience of playground games, collecting information about their own lived experience, working with previously recorded media and, finally, helping to coconstruct and curate a website which captured project data and made it accessible (British Library, 2011).

As has been noted in relation to this project:

\footnotetext{
"Curating, as a verb, incorporates many sub-components and actions; it suggests at least the following: collecting, interpreting, cataloguing, arranging and assembling for exhibition, and displaying. From the outset, the children were aware that they would be helping in some way to construct a website about the games which they had been helping to collect and record throughout the project. For some of the children the website design offered the possibility of extending the reach of the project by making some of the previously hidden aspects of their playground culture accessible to a potentially vast audience... Each of these skills requires knowledge of how elements can be in dialogue with one another, to suggest specific meanings by their location and juxtaposition in the space onscreen and in the navigational metaphor chosen. This is an active process of working with navigability and intertextuality..." (Potter, 2013)
}

The children contributed to the major outward-facing online presence of the project on the basis of their nascent knowledge of action, agency and makeability in the design of web pages. Researchers recorded pitches by the children for particular designs revealing the heavy personal investment they brought to the project in their sense of performed action on the subject matter, 
their collection, distribution and curatorship of their games, working intertextually alongside those collected by previous researchers (Opie, 1993).

The argument here is that this project bridged the gap between home and school, drawing on the repertoires of skills and dispositions in evidence in other settings. Specifically, it asked children to consider more than representation of a body of knowledge onscreen but how their own cultural capital and their own sensibilities and skills could be reflected in the actual curatorship of the space.

A second project which partially exploited the process of self-curatorship was directly connected with attempting to hear the "learner voice" (Fielding, 2004) on issues connected with home-school transitions in media and technology use (Selwyn, Potter and Cranmer, 2010). The children, aged between 6 and 11 in five primary schools, were themselves trained as researchers, using voice recorders and video cameras with their own focus groups to capture responses to questions about their lived experience of media at home and at school. These self-curated responses drew on experiences which they knew to be different between the two spaces but which provided a commentary on how the membrane might be crossed, as noted at the time:

\begin{abstract}
"Particularly evident...was a desire for change and a plea for greater integration into school of new literacy practices which allowed young people to break free from the constraints shaping the social and pedagogic functions of the school. Pupil engagement with the process suggested that they had a sophisticated understanding of the ways in which the social spaces operate and how their new media use differs in the context of home and school. The desire for change did not appear to spring so much from wanting to engage less with the formal curriculum...so much as from a wish to bring some of the skills and dispositions developed in technology use and media consumption outside school across the membrane boundary between home and school ... into the educational setting. (Potter, 2011)
\end{abstract}

It is important to note that neither of the sets of findings from these pieces of research represent a simple argument about being open purely to "childcentred" content or to open up the curriculum a simple version of subjective experience of media, characterised either by the right as a therapeutic curriculum and by the left as a cultural intervention. They suggest instead that it is about process and action, agency and intervention in curriculum experience in the light of the new curatorship. The debates about knowledge and curriculum have been with us in educational research for a number of years and will continue. The idea of being open to curatorship as a practice and as an area for research in media education pedagogy / andragogy is a proposal which seeks to understand the ruptures and connections between lived experience, learning and teaching and to present mappings for how we can move the debate forward.

\title{
Examples (2): Subject Media
}

Three examples of research with older students, spanning secondary, further and higher education, provide data from pilot projects which appear to be 'scaleable' for broader pedagogic and curricular development for Media Studies and other textualised subject areas in formal education. 
'Subject Media' (McDougall and Peim, 2006) describes the formal, policylegitimated and curriculum-framed teaching and learning of Media Studies with syllabus specifications and assessment outcomes in the form of coursework, exams and awarded qualifications. This context is profoundly different to those discussed above, where teachers, students and researchers worked in more 'free range' conditions to explore home / school, literacy / media literacy relations. In the English context, this includes GCSE (secondary school), A Level (pre-University) and higher education courses in Media, along with vocational equivalents that share conceptual academic frameworks, with more practical application.

The power of 'Subject Media' is exercised in proximal relations to other disciplines - most notably English, and how in the daily work of teaching in institutions, media learning becomes a 'vertical discourse' (Bernstein, 1990) as a conceptual framework is handed down and manifested in the provision of resources, text books and academic accounts, from 'Watching Media Learning' to Masterman's (1985) 'seminal' teacher's guide and more recent 'updates' (McDougall and Potamitis, 2009; Scaratt and Davison (eds), 2012).

So how does the 'digital age' challenge such a vertical discourse for Subject Media and how does a model of curation offer a way forward?

A range of pedagogic research projects were undertaken between 2009 and 2012 with school, college and University students either studying Media directly or a media unit / project in a related subject. All of these projects explicitly looked at issues of textual boundaries, school / out of school boundaries and / or expert / inexpert boundaries. Ethnographic approaches were used for all or part of each investigation and data in each case was analysed with specific attention to how shifts in digital age media exchanges relate to orthodox relationships between teacher / student. In other words, we were interested in how more collaborative and participative student-teacher dynamics could - and might need to - mirror more fluid relationships between media and audience. For this work, we discuss the findings with more explicit regard to curation as a metaphor for these 'ways of seeing' textual education, including media.

Two projects explored the significance of videogame play - as performance - for conventional modes of textual analysis. For the first (Kendall and McDougall, 2009), young male A Level English Lit, Film and Media students who were also players of Grand Theft Auto 4 talked, wrote and blogged about in-game experiences in relation to theories of narrative from their subject's vertical discourses. Particular ways of being in different modalities of textual practice raise important issues for how meaning-making is curated for educational outcomes. Participants play with the game, against and through the game for multiple audiences (us, each other, the online community) performing and re-performing versions of their (partly gendered) selves. This group of 16-17 year old players shared narratives on a social media blog, sharing, accounting for gameworld experiences in the weeks after 
the release of the game and were subsequently interviewed with a set of common questions followed by supplementary enquiries to explore the style and content of their blog posts. What became quickly striking was the manner in which the participants, although on the surface interacting with a text that has been derided for its apparently amoral representation of vice, were contemporaneously curating ironic and reflexive identity performances in 'frivolous' register. Frivolity is what interferes with the disciplining of the world" (MacLure, 2006:1). Such frivolity is largely ignored by formal media education but our research suggests it is central textual agency. The way that this process of negotiated textual identity- performance differed from conventional academic analysis was foregrounded in the students' responses. That there is no singular 'way of being' in a game - more of an event than a text - has clear and present implications for the key concepts of 'Subject Media'.

L.A Noire is distinct from GTA in its dissemination as an event which strives to be a text - a game designed as 'literary'. Understood in this way, we might view this game as being 'easier' to study within the frames of reference of Subject Media - the game has a clear set of genre conventions, intertextuality is thickly layered, there is discernible 'representation' of gender, place, time. We might describe $L A$ Noire as (authorless) literature, within the language game of English Literature education at least, as opposed to the more contemporary converged textual field where multi-authoring pervades. For this project (Berger and McDougall, 2013). English, Film and Media students in A Level and undergraduate study worked collaboratively with teachers to learn gameplay, analyse the game as a text and co-create study materials. Echoing Ranciere (2009), whose ideas about 'indisciplined' pedagogy resonate with both our 'inexpert pedagogy' and our curation metaphor. The 'ignorant schoolmaster' was here working with the gamer-student on an academic deconstruction of a (digitally transformed) 'book' which they - the 'expert' teacher - are unlikely to read (or even be able to). Curating, the emphasis was on resisting any notion that this game is untypical but rather to understand it as presenting the (always-already) 'in between' nature of textual reception and exchange, hitherto at least partly obscured by the insistence of describing the properties of apparently 'contained' texts as epistemologically 'still' enough to 'know.' Put simply, curation allows for them to be moving, as events exhibited always artificially, contained only for the duration of the display. Media students curating this event (Andrews and McDougall, 2012) would, then, find parodic meaning-making in the act of producing an intertextual range of artefacts that, in each case, undermine the complexity of inter-event signification. By undermining - through frivolity - the idea that a game is either 'like a novel' or not, working with text-events in a 'flattened hierarchy' the critical educational questions posed by curation shift from. We move from 'what does the text mean?' to what is reading, what is play, what are the rules for the game of reading and how can we add to the flow of the event? 
We use frivolity here, over parody, hitherto more commonly associated with media production work in education, from MacLure's use of the term for 'what interferes with the disciplining of the world'. (2006:1), as distinct, or a step on from the parodic reinforcement, albeit with a satirical or even a frivolous edge, of the 'source text' at work.

Taking season 4 of the US drama The Wire (which deals with the US school system), another project (McDougall, 2010) experimented with a shift 'from 'doing Media' to 'doing people' by 'mapping' the event of The Wire by the research participants - media undergraduates, postgraduates in media education, teacher trainers, Drama lecturers and youth workers, to their textualised lives. The participant groups were given different methods with which to curate the relation of their lifeworlds to The Wire (conventional interviews, a blog, visual methods, film-making, online fan activity). A 'preferred reading' emerged but this was differently constructed for each group. Media teachers provided an intertextual 'metalanguage' curated as a semiotic chain of meaning (or a 'taxonomy' in their words), with their own identities woven in. Drama lecturers were more comfortable with a discourse of 'cultural value', and more distant from the medium. Though their acquisition of cultural capital was close to their media counterparts, their 'mapping' of the text to their lifeworlds came less instinctively. The youth workers curated the preferred reading by articulating 'real' situations and the text was much more obviously a stimulus for curation of experience. For the trainee teachers, proximity to the social reality represented was similar to the youth workers, but framed as vocationally-driven optimism for change. This data showed that teaching "about" The Wire was secondary to the more experimental and reflexive work with people. The reasons for the nuances and markers in the data from each group are not only a product of location in educational social practice but also by the learning context, which was different for each group. This kind of 'mash-up ethnography' also moves away from the 'still' text to how people in culture attribute meaning to media - the moving event.

The final project of interest here involved 13-14 year old Citizenship students making documentary films to explore ideas about local, national and European identity. This was more about 'making' but the pedagogic shift was to require the films to be ethnographic so the students could reflect on the power of the edit, with a clear brief to provide 'thick description' of community viewpoints about Europe. In working ethnographically, students making the documentary films were at the same time the 'subjects' (agents) and 'objects' (the data) of the learning and the research. Data was captured in three forms - the documentary films produced by students, uploaded to the project's website and screened at two international film festivals; individual interviews with teachers and group interviews with participating students. The research questions related to the potential of this pedagogic intervention for reflexive learning in Citizenship to successfully work in the "interplay between contexts for action, relationships within and across contexts, and the dispositions that young people bring to such contexts and relationships" (Biesta, Lawy and Kelly, 2009: 5). In the analysis, of course, such aspirations for this 'discipline' are transferable to all pedagogy and can be most coherently formulated, 
again, in the act of curation. The extent to which students would be comfortable with this approach - compared to their 'instinctive' familiarity with both conventional media and its profoundly non-ethnographic modes of representation and conventional learning with equally profound hierarchies of expertise and transmission - was the focus of interviews with students and teachers during and after the intervention. In the responses, teachers shared positive experiences in terms of 'engagement' and beyond this, two further levels of practice were identified. Firstly, students thinking (for themselves) about identity issues in ways that seemed to have arisen experientially - or dialogically, in terms of 'going out' to find their own contexts for learning - out of the school into the community, another 'membrane' to permeate. Secondly, the teachers instinctively translated their observations into a discourse of 'skills' - of participation and action. The potential for using 'easy' media to more formally 'map' this kind of work an ethnographic mode of curation would, we suggest, move teachers in all subject contexts, embracing their 'inexpertise', to the more genuinely constructivist pedagogy most practitioners would endorse.

These findings, like the projects undertaken with younger children, provide compelling evidence that lived experience, media and the act of curation can be brought together by new pedagogical models that move away from 'fixed' boundaries between home and education, learning and play, types of text, media and people and most importantly, expert and learner. The difference is that these new ways of seeing media education are much harder to develop in the more constraining institutional framing of 'Subject Media' than in the potentially more 'free range' contexts in which primary school children operate. This is stunningly ironic.

\section{Going forward}

The implications of the various research findings outlined above for media education are clear. The long-running debate around media education in and for the digital age has consistently given far more weight to the 'nouns' of the curriculum than to the 'verbs' of pedagogy. For this fundamental reason, the community of practice has been stuck on the 'working out' of these design principles.

This way of thinking about media education reframes the (incomplete) project by accepting first that new digital media have not in themselves caused much to change. But they have allowed educators to see more clearly the problem of reducing media learning to producer / audience and teacher / student interactions and, we argue, potentially see curation as a solution. But this problem was always there and the proposed solution always available.

Looking at some of the more fluid kinds of practice at work in arts education can help us turn our attention to the 'making' of learning (Orr and McDougall, 2013). For example, recent research in design pedagogy on students as 'native' inhabitors of 'ecotonal' margin spaces (before they are institutionalized by curricular insulations) is helpful in thinking through how 'transmedia' 
exchanges might be mirrored by a more open, porous form of expertise as well as a pedagogy / andragogy of 'indiscipline' (from Ranciere, 2009). Such very deliberate disruptions to the order of things can "replace hierarchical constraints with an alternate model of heregeneity and multiplicity" (Pendleton-Jullian, 2012: 46). But we are acutely aware that such 'rhizomic' ideals are easy to write about but less clearly applicable on Monday morning with year 9. To this end, we conclude with three strategies for a media pedagogy / andragogy of curation which take us back to the key themes of 'Watching Media Learning', and then forward.

\section{From Watching to Curating}

At stake in discourses of media literacy, education and pedagogy / andragogy are fundamental questions about what it means to be an expert in relation to textual practices. These go beyond media education, but we can observe them more clearly in the spaces and places where 'everyday' media practices are bound up with, and compete alongside vertical discourses of academic work. Our key argument here is that, whilst digital and online media do not in themselves determine any profound shift in these epistemological configurations, they do rather 'force the issue' that was already there - and has been discussed since 'Watching Media Learning' and before.

The practice of asserting truths about children, youth and media, and the circulation of such assertions through journals, conferences, university courses, newsletters, websites and so on, operate in ways that establish or challenge notions of expertise. Dehli, 2009: 60

So to conclude with three recommendations for curating media learning in the digital age with adherence to the enduring but as yet elusive Vygotsyian principles:

(1) Firstly, knowing that practices, resources and artefacts of lived experience are not easily transmissible across the membrane between home and school, educators need to focus instead on the skills and dispositions evident in the one which can support and develop the other. From home, the tactics and strategies of managing multiple presences, anchored and transient affiliations (Merchant, 2005) in a dynamic and seemingly always-visible space; from school, in the other direction, a criticality and distance provided, in the best of these settings, in a moderated place of safety which seeks to work with the habitus and cultural capital of students and young people. In 'Watching Media Learning", Chris Richards observed the challenges for a media education posed by the constraints of broader pedagogic power structures, as inevitably "Teaching takes place within conditions which are not of its own choosing and its power to intervene in the formation of others, though considerable, is itself historically variable and limited". (1990: 167-8). Two decades on, the profoundly artificial 'in between' space of education should become the explicit focus of media pedagogy as opposed to an 'inconvenient truth'. This will look like a kind of ethnography of mediation across home-school boundaries, rather than the hegemonic intervention in (textual) subjectivity enacted only on the terms of educators exercising power. 
In practice, this means helping students to experiment with key principles of mimesis (Willett, Robinson and Marsh, 2012: 127-8), transgression and selfreflexion - but, crucially, at no point are we to understand these as somehow innate to young people in digital spaces - these are the approaches we need to teach. Making self-representational texts involves organizing and reordering on and offline, analogue and digital textual practices - acts of assemblage. These are not a given, in some kind of digital native utopia. Instead, in this sense, 'media production' moves away from either confirming or challenging the conventions of 'real' texts from 'the media' and becomes an auto-ethnographic making of textual meaning and, ultimately, of knowledge (of the self). The nature of educational space as an 'in between' habitus becomes itself the object of study, fostering genuine 'proximal development' of criticality.

(2) Secondly, establishing circles of trust, already suggested in research from primary schools (Selwyn, Potter and Cranmer, 2010) in which students have a voice which exercises some control over the spaces and facilities which are available to them inside school. Voice is far from neutral, however. We are, here, articulating Couldry's (2010) conception of the sociology of voice as providing a space for "the conditions under which we can give accounts of our lives and to how these accounts are valued, or perhaps not valued at all (2010: 113)." We suggest that media education has paid insufficient attention to the pedagogic framing of the (textualised) lives of students. Curation is profoundly to do with this kind of textual accounting. In 'Watching Media Learning', Jenny Grahame speculated that a new agenda for media education might arise from a more negotiated "interface between 'our' theory and 'their' practice" in which "we begin to reconcile our notion of appropriate learning with what they perceive as important to them" (1990: 121). Two decades on, we argue that, again, digital media in themselves do not facilitate such reconciliation but the fact that the kinds of media production set up by Grahame are more likely to occur in the 'lifeworld' - not only in the media classroom - means that textual practice travels along the membrane between 'coursework' and informal learning. Or rather, it always did but it's now harder to ignore.

In practice, this means a genuine co-creation of knowledge between teacher and student. One obvious example is game texts. In very simple terms, it is impossible to 'know' a game in the same way as one might claim to be an expert on a book for film. Students will arrive with more expertise merely by virtue of age and lifestyle differences, as well as priorities and degrees of 'distinction' (1984). Taking gameplay experiences as reading that 'counts' epistemologically and then extending this idea of student expertise and teacher 'scaffolding' (another Vygotskian theme) to ALL contemporary mediation will develop a more performative and embodied media learning. Again, it is not digital gameplay that determines this shift, but it can be a catalyst for belated moves of this kind.

(3) If the boundaries between technology and user, text and reader, media and audience are to be curated as fluid and unstable, then so to must the boundaries between being a teacher and being a student, being an expert or 
'lacking' the capacity to be so. So finally, and arising from the previous strategies and everything suggested here to this point, it is clear to us that the design of media pedagogy must shift to make the 'educational encounter' match the proliferation of deconstructed, fragmented transmedia reading and making practices. Put simply, our curation pedagogy embraces the status of the inexpert educator - from Ranciere's 'ignorant schoolmaster' (2009). Going further, we want to mirror transmedia with a pedagogy of blended expertise, so that knowledge and authority - the mantle of the expert - also travel along the membrane between home and school. This is fundamentally not to do with wanting to be 'down with the kids', as critics of the over-polarised 'Media 2.0' debate are so quick to level. Instead, and perhaps ironically, it seems abundantly obvious that such a deliberate 'matching' of media / teacher and audience / student - to arrive at the concept formally known as the expert, perhaps, will bolster precisely the aspirations Buckingham expressed for media education 'back in the day'. If we understand education to be a language game, then we can utilize the way that contemporary digital media deconstruct text-reader relations to do the same to teacher-student dynamics in order to "enable students to understand language itself to empower them still further" (Buckingham, 1990: 225).

In practice, this means very simply that teachers must learn from students about how flattened value hierarchies operate in contemporary reading practices. There is no way most teachers can be savvy with this. Not 'down with the kids' but simply respecting time served in textual fields as not only 'pleasure' but also expertise, not to be regulated or channeled into something abstractly theoretical but to be utilized and given value on its own terms.

In summary, we believe that the 'digital age' brings to the surface longstanding and unresolved questions about media learning that, despite the best intentions of our community of practice, remain unresolved. The reason for the incomplete nature of the project of media education can be attributed to the failure to focus on pedagogy, caused by the centrality of curriculum in the operation of schooling as social practice and an unhelpful interest in looking at, or training for 'the media'. A pedagogy framed as curation can help return us to these old questions with a renewal of aspiration, but only with a radical 'reboot' of how we design media learning, towards a porous expertise.

\section{References}

Andrews, B. and McDougall, J. (2012) 'Curation Pedagogy: Further Toward the Inexpert' in Medijkske Studije 3(6): 152-167.

Bennett, P., Kendall, A. and McDougall, J. (2011) After the Media; Culture and Identity in the $21^{\text {st }}$ Century (London: Routledge).

Berger, R. and McDougall, J. (2011) 'Media Studies 2.0: A Retrospective', Media Education Research Journal (2)1: 5-10. 
Berger, R and McDougall, J (2013) 'Reading Videogames as (Authorless) Literature in Literacy: in press.

Bernstein, B (1996) Pedagogy, Symbolic Control and Identity: Theory, Research, Critique. London: Taylor and Francis.

Biesta, G, Lawy, and Kelly, N. 2009. 'Understanding young people's citizenship learning in everyday life; The role of contexts, relationships and dispositions'. Education, Citizenship and Social Justice March 2009 vol. 4 no. 1 5-24.

Bourdieu, P (1984) Distinction: A Social Critique of the Judgment of Taste. London: Routledge.

British Library (2011) Playtimes: A century of children's games and rhymes. http://www.bl.uk/playtimes [accessed $3^{\text {rd }}$ June, 2011]

Buckingham, D (ed), 1990. Watching Media Learning: Making Sense of Media Education. London: The Falmer Press.

Burn, A. 2009. Making New Media: Creative Production and Digital Literacies New York, Peter Lang.

Bulfin and Koutsogiannis, 2012. 'New Literacies as Multiply Placed Practices: Expanding Perspectives on Young People's Literacies across Home and School' in Language and Education, v26 n4 p331-346.

Couldry, N (2010) Why Voice Matters: Culture and Politics after Neoliberalism. London: Sage.

Curran, J., Freedman, D. and Fenton, N. (2012) Misunderstanding the Internet London: Routledge.

Dyson, A. H. (1997). Writing superheroes: Contemporary childhood, popular culture, and classroom literacy,. Williston, VT: Teachers College

Fielding, M. (2004), 'Transformative approaches to student voice: theoretical underpinnings, recalcitrant realities'. British Educational Research Journal, 30 (2), 295-311.

Fraser, P. and Wardle, J. (2011) in A Manifesto for Media Education, available from: http://www.manifestoformediaeducation.co.uk/ [accessed 28 June 2012]

Fraser, P and Wardle, J (eds). 2013 (forthcoming). Current Perspectives in Media Education. London: MacMillan.

Jewitt, C. (ed.) 2011. The Routledge Handbook of Multimodal Analysis, London: Routledge. 
Kendall, A and McDougall, J. (2009) 'Just Gaming: On Being Differently Literate' in Eludamos: Journal of Computer Game Culture . vol 3 (2), p. 245260

Kendall, A. and McDougall, J. (2012) 'Critical media literacy after the media: can we see clearly now?', in Tyner, K. and Gutiérrez-Martin, A.

(Eds) Alfabetización mediática en contextos digitales múltiples, Revista Communicar 38. (Andalucia, Spain: Grupo Communicar).

Kress, G. 2003. Literacy in the new media age, London, Routledge.

Livingstone, I. (2012) Presentation to Media Education Summit, Bournemouth University, September, 2012

Livingstone, S; Papaioannou, T; Perez, M and Winjen, C. (2012) 'Critical Insights in European Media Literacy Research and Policy' in Medijkske Studije 3(6): 152-167.

MacLure, M (2006) 'Entertaining Doubts: On Frivolity as Resistance' in Satterthwaite, J, Martin, W and Roberts, L (eds) Discourse, Resistance and Identity Formation. London: Trentham: 5-20.

Masterman, L. (1985) Teaching the Media. London: Routledge.

McDougall, J and Peim, N (2007) 'A Lacanian reading of the study of Big Brother in the English Curriculum'. Changing English, vol 14 (3): 299-312.

McDougall, J, (2010) 'Wiring the Audience' in Participations Vol 7 Issue 1: 73101

McDougall, J and Potamitis, N (2010) The Media Teacher's Book $2^{\text {nd }}$ edition. London: Hodder.

McDougall, J (2013) 'It's hard not to be a teacher sometimes: Citizen ethnography in schools' in Citizenship, Teaching and Learning. ADD VOL + PAGES.

Opie, I. (2003) The People in the Playground. Oxford: Oxford University Press

Orr, S and McDougall, J, 2013 (in press). 'Towards a mirror: the learning and the work in a partnership of equals' in Cleaver, $E$, Lintern, $M$ and McLinden, $M$ (eds) Teaching and Learning in Higher Education: Disciplinary Approaches to Research. London: Sage.

Pendleton-Jullian. (2009) Design Education and Innovation Ecotones http://fourplusone.wordpress.com/design-education-and-innovation-ecotones/ (accessed 30.5.13) 
Potter, J. (2011) "New literacies, new practices and learner research: Across the semi-permeable membrane between home and school" in Lifelong Learning in Europe Vol. XVI, ISSN: 1239-6286 issue 3/2011 pp. 174-181, Kansanvalistusseura: Helsinki, Finland

Potter, J. (2012) Digital Media and Learner Identity: The New Curatorship. New York: Palgrave MacMillan.

Potter, J. (2013, forthcoming) "Co-curating children's play cultures" in Burn, A \& Richards, C (ed) Children's games in the new media age: Childlore, media and the playground, Ashgate: Burlington VT

Ranciere, J (2009) The Emancipated Spectator. London: Verso.

Scarratt, E and Davison, D (eds) (2011) The Media Teacher's Handbook. London: Routledge.

Selwyn, N., Potter, J. \& Cranmer, S. (2010) Primary schools and ICT: Learning from Learner Perspectives, London: Continuum

Street, Brian V. (1995). Social literacies: Critical approaches to literacy in development, ethnography and education. London: Longman.

Teachmeet Wiki (2013) http://teachmeet.pbworks.com/w/page/19975349/FrontPage [Accessed 12th April, 2013]

Vygotsky, L (1978) Mind and Society: The Development of Higher Psychological Processes. Cambridge, MA: Harvard University Press.

Walters, E (2011) 'Time for Media Education to Come Out of the Closet' $A$ Manifesto for Media Education:

http://www.manifestoformediaeducation.co.uk/2011/07/emma-walters/ [accessed 31.5.13]

Wenger, E (1998) Communities of Practice: Learning, Meaning and Identity. Cambridge: Cambridge University Press

Willett, R, Robinson, M and Marsh, J (2012) Play, Creativity and Digital Cultures. London: Routledge. 


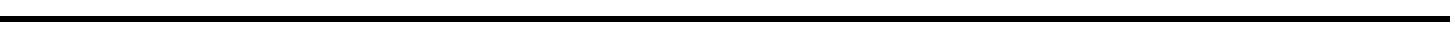

